\title{
THE ANTECEDENTS OF IMPULSE BUYING BEHAVIOR DURING COVID-19 PANDEMIC: REVEALING THE ROLE OF PANIC BUYING, GOVERNMENT STIMULUS, PERCEIVED SCARCITY, AND FEAR APPEALS
}

\author{
Alfian Budi Primanto ${ }^{*}$, Rahmawati ${ }^{1}$ \\ 'Management Department, University of Islam Malang \\ Address: ' Jl. Mayjen Haryono No. 193, Dinoyo, Lowokwaru, Malang, Jawa Timur, Indonesia 65141 \\ *E-mail: alfianprima@unisma.ac.id
}

\begin{abstract}
COVID-19 pandemic spread around the world and changed people's shopping habits. This phenomenon causes much fear and induces panic behavior. In a highly uncertain situation, many people are more likely to engage in impulse buying behavior during this period. Our research aims to examine that impulse buying behavior during the pandemic. Hypothesis testing in this study uses the path analysis technique, which is processed using a computer with a program that has been developed by Preacher-Hayes, namely the Macros PROCESS technique. The research finds that panic buying, government stimulus, perceived scarcity, and fear appeal have a significant direct effect on impulse buying behavior. We went a step further to test the indirect effects. The indirect test supports our hypothesis by using fear appeal as mediating variable. The result indicates that fear appeal mediates between panic buying, whereas impulse buying behavior has no significant effect. Furthermore, fear appeal mediates between government stimulus, and scarcity of essential products has a significant effect on impulse buying behavior.
\end{abstract}

Keywords: Impulse buying behavior, panic buying, government stimulus, perceived scarcity, fear appeal

JEL Classification: M30

\section{Article History:}

Received: September 11, 2021; Revised: November 15, 2021; Accepted: November 22, 2021; Available Online :

December 12, 2021

DOI: $10.20473 / \mathrm{jmtt.v14i3.29886}$

\section{INTRODUCTION}

Covid-19 has affected human life globally. To prevent the spread of COVID-19, individuals have changed the amount of their production to consume daily needs. They have an impact on significant disruption of consumer behavior (Sheth, 2020). This phenomenon also causes a lot of individual fear and panic that interferes with buying behavior and shopping habits (Naeem, 2020); Sheth, 2020). The consumer makes an excessive purchase because of pressure from the current situation (Anastasiadou et al., 2020).

In an uncontrollable situation, consumers will explore all channels to buy products online and offline in bulk in anticipation of high prices and product scarcity (Chua et al., 2021). As a result, there is a lack of products for daily needs, food, and other medical needs (Huang and Zhao, 2020; 
David, Visvalingam, and Norberg, 2021). This phenomenon occurs in response to the fear of scarcity, information bias, social learning, and lack of trust or distrust of authority (Arafat, Kar, Menon, 2020).

When a disaster occurs, such as a health crisis, consumers seem to stockpile some essential and non-essential products because the government implements several policies to limit the massive spread of Covid-19 (Grohol, 2020; Sheth,2020). So that makes consumers feel panicked and afraid if the product suddenly runs out of stock and supermarket shelves are empty because of panic buying (David, Visvalingam, and Norberg, 2021). Wei, Wen-Wu and Lin (2011) recognize this behavior as panic buying in which consumers buy very large quantities of a product or a very diverse range of products in anticipation of, during, or after a disaster or perceived disaster or in anticipation of shortages or high price increases. When other consumers become panicked, they can increase the desire to panic buying and result in herd behavior under such conditions (Baddeley, 2010; Loxton et al., 2020; Zheng, Shou, and Yang, 2021). There is a positive correlation between panic buying scale and impulse buying, which means that the higher the tendencies of panic buying that scaled by consumers, the higher the possibilities of the consumer to buy impulsively ((Lins and Aquino, 2020))

Some research related to impulse buying behavior during health crises and disasters, such as the COVID-19 pandemic. Digital technology plays an important role in spreading news during a pandemic that can trigger emotional states of fear, and individuals have been placed on a resilience approach (Crabble,2020.). Thus, in the context of the fear-inducing COVID-19 phenomenon, impulse buying behavior has significantly increased across the world (Wiranata and Hananto, 2020; Addo et al., 2020). Consumer characteristic is the most dominant factor affecting a person's tendency to impulsive buying behavior (Halim et al., 2017). Moreover, TS Chein, OT Hui (2020) stated the act of an unplanned, spontaneous, and almost instantaneous purchase is an integral part of the human race. Also, impulsive buying can be influenced by behavior both internally and externally. A new scenario seems to be opening up where customers enter the store much more prepared than in the past, searching for products they had planned to buy (Bellini, Cardinali, and Grandi, 2017). Furthermore, L. T. Huang (2016) stated that reactive and affective factors are important stimuli in facilitating impulse buying behavior. Parsad (2020) characterized an impulse purchase pattern, as impulse buying occurs when consumers experience an expected, intense, and continual impulse to buy something immediately. 


\section{Alfian Budi Primanto \\ Rahmawati}

Our primary goal is to examine a predictive model of impulse buying behavior by including panic buying, government stimulus, perceived scarcity, and the mediating role of fear appeals as additional predictors of impulse buying behavior. According to Ahmed et al. (2020), Crabble (2020), and Addo et al. (2020), government stimulus plays a significant role in increasing impulse purchase behavior. As a result of this unexpected stimulus benefit, people with extra money often used their money to buy both essential and (mostly) non-essential products. Chua et al. (2021) also added that in a crisis like COVID-19, consumers' perceived scarcity would likely increase perceived price insecurity and stock unavailability. Thus, it will increase their degree to buy impulsively immediately. They will foresee themselves regretting if they do not get their products before they are stocked up. Fear appeals, therefore, will mediate the effect of panic buying, government stimulus, perceived scarcity on impulsive buying behavior. Öhman (2005) and Naeem (2020) stated that fear is a universal trigger of impulsive buying behavior that may be enhanced because of the threat of harm, especially during the COVID-19 pandemic.

\section{LITERATURE REVIEW AND HYPOTHESES}

\section{Impulse Buying Behaviour}

The economic crisis during the pandemic and the impetus of digital technology triggered a significant change in shopping habits especially impulse buying behavior. Impulse buying is an abrupt and immediate purchase with no intention to buy before (Beatty and Ferrell, 1998) tendency to make an unplanned purchase (Jones et al., 2003). The current study defines impulse buying as an unplanned consequence of exposure stimulus and deciding to buy straightway (Piron, 1991). Thus, Kacen and Lee, 2002 described impulse buying behavior as spontaneous purchase indicated by relatively fast decision making and subjective tendency.

The coronavirus is a huge hit that can change consumer behavior. They over-purchase due to some pressure (Anastasiadou et al., 2020). impulse buying is influenced by reactive and affective factors and occurs when the consumer experiences an expected, intense, and steady urge to buy something outright (Huang, 2016, Parsad, 2020). Furthermore, the phenomenon Covid-19, impulse buying behavior has significantly affected worldwide (Wiranata, Hananto, 2020, Addo et al., 2020, Gupta et al., 2021) revealed that the COVID-19 pandemic significantly affects consumer behavior patterns denoted by stockpiling and impulse buying behavior.

\section{Panic Buying}

Consumer panic arises when a disaster or health crisis occurs. Panic buying is a complex behavior driven by multiple motives and psychological processes (Dholakia, 2020; Chua et al., 2021). It is 
usually formed as a psychological reaction in response to perceived scarcity, stress, a sense of losing control, insecurity in a certain situation (Arafat et al., 2020; Hendrix and Brinkman, 2013). From a psychological view, Clee and Wicklund (1980) defines panic buying as a perceived need for an object threatened when consumers feel out of stock for a particular product they experienced, resulting in a perceived loss of control. Thus, panic buying is usually considered a cognitive aspect and an affective aspect of the unconventional consumer. Two main aspects also influence panic buying: intention and behavior, which is mass psychology that plays a major role (Xie LR, Chen JM, 2020). Panic buying is a socially undesirable herd behavior when a large quantity of an important product or drug purchased by a consumer affects product scarcity (Steven, 2020). A perception of scarcity is closely related to panic buying of specific product item, while this behavior can be driven by lack of trust and reduce consumption (Dholakia, 2020).

When the World Health Organization declared the COVID-19 pandemic, at that time, many shelves in supermarkets were emptied because of panic buying (David, Visvalingam, and Norberg, 2021). Panic buying has implications for buying consumer goods in large quantities due to disasters or health crises (Yuen et al., 2020). Psychologically, stockpiling storable goods could give consumers a sense of aegis from the crisis (Grohol, 2020). However, consumer panic buying behavior can cause supply effect disruption (Peels et al., 2009). When other consumers are seen to panic buying, they may increase motivation to panic buy and resulting herd behavior (Loxton et al., 2020; Zheng, Shou, and Yang, 2021; Baddeley, 2010). Generally, panic buying increases the fear of hoarding. If consumers engage in delinquent behavior, they make impulse purchases of essential or non-essential products (lyer et al., 2019). Based on the background review, we proposed the hypothesis below:

\section{H1a. Panic buying has a significant effect on fear appeal}

\section{H1b. Panic buying has a significant effect on impulse buying behavior}

\section{H1c. Fear appeal has a significant effect on impulse buying behavior on Model 1}

\section{Government Financial Stimulus}

The COVID-19 pandemic has had a direct impact on the economy in several ways. Governments must provide financial stimulus to support their communities to survive in uncertain situations (Siddik, 2020). Governments around the world are implementing several financial stimuli such as monetary and fiscal policies targeting healthcare, households, service industries, manufacturing, and other key sectors (Bayer, 2020.; Cheng et al., 2020). In the household sector, most consumers said that they would buy groceries and other essential items. However, some middle-class shoppers vowed to save this money during hard times (Numerator Intelligence, 2020.) 


\section{Alfian Budi Primanto \\ Rahmawati}

Moreover, people have spent this money on groceries items, sanitary, beer, and lottery. Thus, most of them purchase non-essential items because of their impulsive buying behavior (Addo et al., 2020). Based on the background review, we proposed the hypothesis below:

\section{H2a. Government financial stimulus has a significant effect on fear appeal}

H2b. Government financial stimulus has a significant effect on impulse buying behavior

H2c. Fear appeal has a significant effect on impulse buying behavior on Model 2

\section{Perceived of Scarcity of Essential Product}

Based on psychological reactance, people's perceived scarcity tends to vary in their chronic tendencies to react to or threats to freedom (Gong, Zhang, and Fan, 2021). Furthermore, OsésEraso, Udina, and Viladrich-Grau, (2007) argued that scarcity signifies a loss of freedom. Consumers tend to want products on which these boundaries are placed. Product scarcity is the lack of access to products and services offered by marketers (Hamilton et al., 2018). Previous research on product scarcity suggests choice restrictions induced by a lack of access to a specific product can increase consumers psychological reactance (Brehm, 1966) which may increase the desirability of the product (Fitzsimons, 2000; Clee and Wicklund, 1980)

News of Covid-19 has dispersed around the world. The supermarket is overstocked with essential products but suddenly gone for a few minutes because consumers panic buying. (Crabble, 2020; Kim and SU, 2020). An important aspect that supermarkets must consider is logistics management because they have previous experience with empty shelves. Of course, supermarkets will be able to manage logistics better (Anastasiadou et al., 2020). The scarcity of goods due to excessive demand makes consumers feel afraid of attraction, so that it can cause turmoil to buy excess products (Keane and Neal, 2021). When seeing the queves at supermarkets with unusual queves at the beginning of the spread of Covid 19, consumers realized that they had to stock up on essential products. (Suryaningsih and Suryaningsih, 2020). In addition, social media has a significant impact by spreading images of empty shelves and long queves of consumers, which increasingly tempts people to make impulse purchases to buy and hoard important and nonessential goods through online and offline stores. (lyer et al., 2019; Addo et al., 2020). Based on the background review, we proposed the hypothesis below:

H3a. Scarcity of essential products has a significant effect on fear appeal

H3b. Scarcity of essential products has a significant effect on impulse buying behavior

H3c. Fear appeal has a significant effect on impulse buying behavior on Model 3 


\section{The Mediation Role of Fear Appeals}

Fear is one of the basic emotions of a human. Fear may be felt after a conscious assessment in a dangerous condition (Poels and Dewitte, 2006) and grows as an instrument to protect oneself from threatening situations (Addo et al., 2020). A fear appeal consists of three determinant variables: perceived efficacy, threat, and fear (Riordan and Singhal, 2018) Similar to MB et al. (2015), fear appeals encourage consumers to cognitively deal with a depicted threat. The outcome of this processing effort may bias their decision.

Covid-19 is a matter of serious concern: the attraction of fear that can certainly trigger impulse buying behavior. Another study also associated impulse buying with fear (Lin and Chen, 2012). However, there are no outward signs of improvement and change in the COVID-19 pandemic. People must face or prevent and fight against it. Thus, the public reacted in several ways. They bought essential items and overstocked their homes, staying at home to isolate themselves. They are intensely involved in buying groceries, beer, cleaners, and toilet paper (Addo et al., 2020). Thus, several studies suggested that the Fear appeal is an important mediating variable during impulse purchase behavior (lyer et al., 2019; Addo et al., 2020). Based on the background review, we proposed the hypothesis below:

H4: Fear appeals mediates the relationship between panic buying and impulsive buying behavior positively.

H5: Fear appeals mediates the relationship between government stimulus and impulsive buying behavior positively.

H6: Fear appeals mediates the relationship between perceived scarcity and impulsive buying behavior positively.

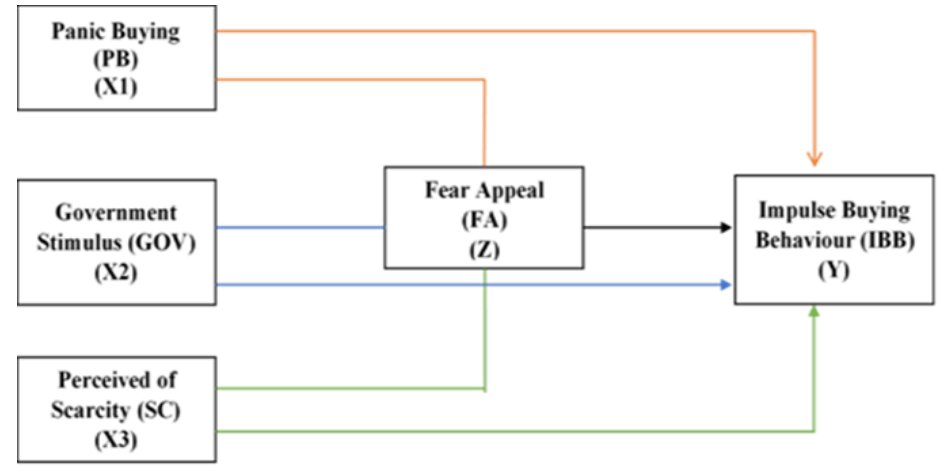

Figure 1.

Research Framework

Source: Author 2021 


\section{Alfian Budi Primanto \\ Rahmawati \\ RESEARCH METHODS}

This study can be categorized as quantitative research. This study aims to investigate and examine the influences of panic buying, government stimulus, perceived scarcity, and the mediation role of fear appeals on impulsive buying behavior with a survey questionnaire. All the items of each construct were answered on a five-point Likert Scale (5- Strongly Agree, 4- Agree, 3-Neutral, 2Disagree, and 1-Strongly Disagree). Sampling criteria for this research were (1) Living in Indonesia, (2) having monthly income, (3) respondent's age criteria must be above 18 years old, and (4) having mobile devices. We were deploying the questionnaire in several big cities in Indonesia, such as Jakarta, Surabaya, Padang, Bali, Probolinggo, Makassar, Malang, etc. Because of the COVID-19 pandemic and health protocols, we used random sampling to get the potential respondents. A total of 301 respondents were collected in this study. The survey was entirely returned to about 269 respondents, but 243 respondents had completed the task with valid criteria to meet the survey criteria.

Hypothesis testing in this study uses path analysis techniques processed using a computer with a program developed by Preacher-Hayes, namely the Macros PROCESS technique. Hair et al. (2010) stated that when testing the effect of mediation, researchers should follow Preacher and Hayes and bootstrap the sampling distribution of the indirect effect coefficients used in simple mediation models. The bootstrap approach does not require the assumption of a variable distribution or sampling distribution of a statistic. It can be applied to small sample sizes. For direct effect evaluation, the PROCESS result should show that the value of t-tested between variables was lower than 0.05. On the other hand, for indirect evaluation, zero value between the bootstrapped lower level confidence interval (LLCI) and upper-level confidence interval (ULCI) confirmed a mediation effect between variables.

From this research framework, we have three sub-structural path models. These three substructural models directly affect panic buying, government stimulus, perceived scarcity, and fear appeal toward impulse buying behavior. Table 1 below will be described the three sub-structural models: 
Table 1.

Sub structural Model Direct Effect

\begin{tabular}{cc}
\hline Model & Variable \\
\hline \multirow{2}{*}{ Model 1 } & PB - FA \\
& PB - IBB \\
Model 2 & FA - IBB \\
\hline \multirow{2}{*}{ Model 3 } & GOV - FA \\
& GOV - IBB \\
& FA - IBB \\
\hline SC - FA \\
SC - IBB \\
FA - IBB
\end{tabular}

We also examine the indirect effect of whether the fear appeal can mediate between panic buying, government stimulus, and perceived scarcity. The indirect effect variables will be shown in table 2 below:

Table 2.

Indirect Effect

\begin{tabular}{cc}
\hline No & Variable \\
\hline 1 & PB - FA - IBB \\
2 & GOV - FA - IBB \\
3 & SC - FA - IBB \\
\hline
\end{tabular}

\section{RESULTS AND DISCUSSION}

\section{Demographic Analysis}

A total of 243 respondents were gathered in this research. They consist of $52,3 \%$ female and $47,7 \%$ male. Our data be composed of $85,6 \%$ from the age bracket 18 - 30 years old. Furthermore, 10,3\% from the age bracket $30-40$ years old and the last were $0,1 \%$ from the age bracket above 40 years old. However, responses were received from all socioeconomic classes, where $49.8 \%$ of respondents belonged to the low social class, $40 \%$ of the respondents belonged to the middle class, and $10.25 \%$ belonged to the upper social class. In terms of employment, $70.1 \%$ have jobs in several sectors such as government employees, companies, lecturers, entrepreneurs, freelancers, etc. Then $20.4 \%$ are freelancers, and the last $9.5 \%$ are unemployed.

\section{Validity Test and Reliability Test}

The interpretation of the instrument validity is made using valid and invalid criteria limits, as shown in the correlation table. If $r$-Value > rtable, then it is said to be "valid," and if $r$-Value < rtable, it is said to be "invalid". Based on table 3, all variables are valid, r-value > r-table. 
Table 3.

Validity Test

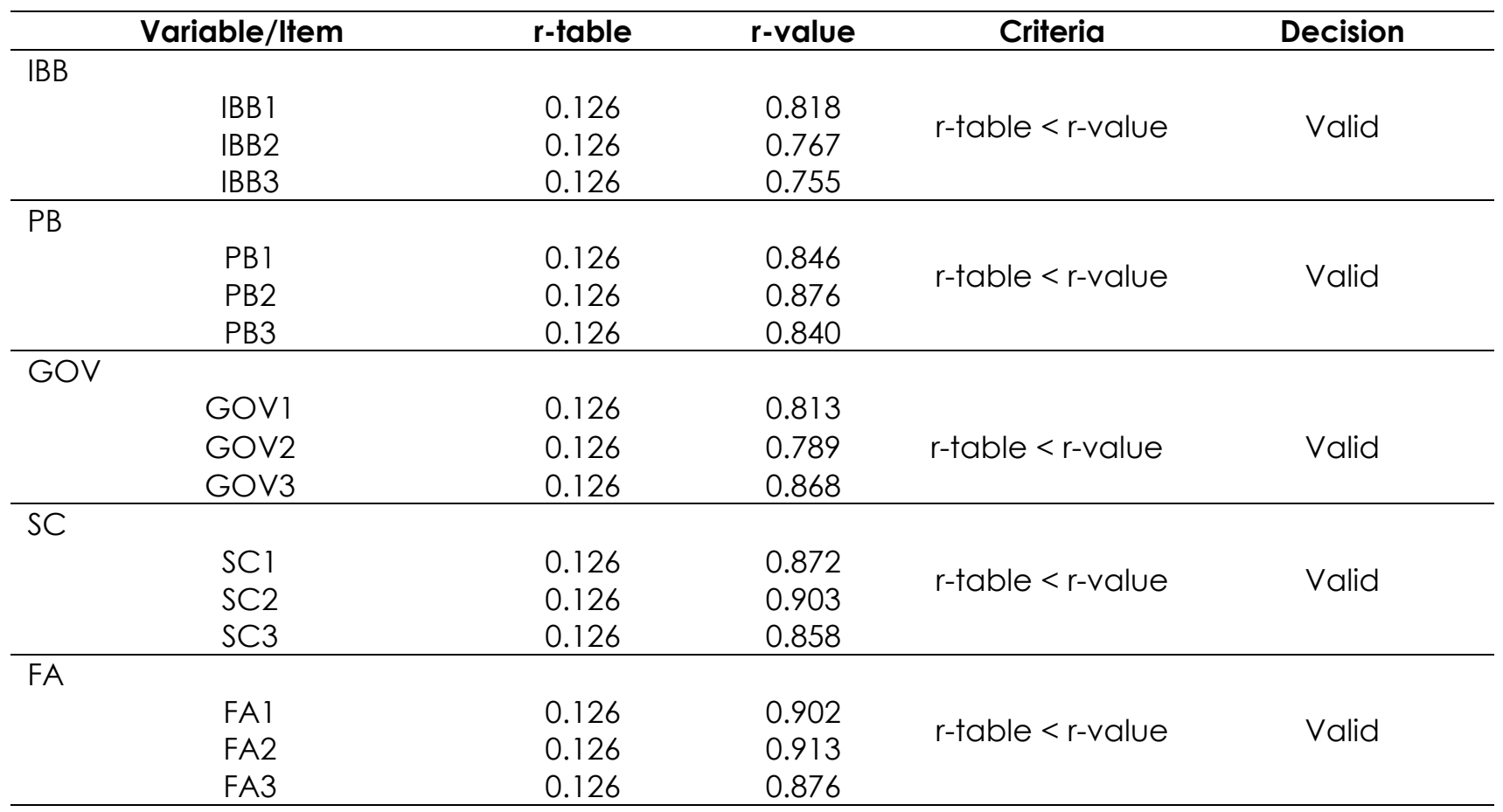

To determine the instrument's internal consistency in terms of reliability, Cronbach's Alpha was calculated for the correlation between each test item and the remaining items or their total (total score). Although a determinant value higher than 0.7 is considered ideal, a value below 0.7, close to 0.6 , can be considered reliable. Table 4 below describes the results of the reliability test. Cronbach Alpha value is greater than 7, and 1 variable, namely IBB close to 7, means reliable.

Table 4.

Reliability Test

\begin{tabular}{cccl}
\hline Variable & Criteria & Cronbach Alpha & Decision \\
\hline IBB & $>0.600$ & 0.673 & Reliable \\
PB & $>0.600$ & 0.814 & Reliable \\
GOV & $>0.600$ & 0.761 & Reliable \\
SC & $>0.600$ & 0.850 & Reliable \\
FA & $>0.600$ & 0.879 & Reliable \\
\hline
\end{tabular}

\section{Sub structural Model Direct Effect}

Based on the results of Macro PROCESS to test the direct and indirect effects of exogenous variables on endogenous, the results obtained are: 
Table 5.

Sub structural Model Direct Effect

\begin{tabular}{ccccc}
\hline Model & Variable & Criteria & p-value & Decision \\
\hline \multirow{3}{*}{ Model 1 } & PB - FA & $<0.050$ & 0.000 & Accepted \\
& PB - IBB & $<0.050$ & 0.000 & Accepted \\
& FA - IBB & $<0.050$ & 0.027 & Accepted \\
\hline \multirow{3}{*}{ Model 2 } & GOV - FA & $<0.050$ & 0.000 & Accepted \\
& GOV - IBB & $<0.050$ & 0.013 & Accepted \\
& FA - IBB & $<0.050$ & 0.000 & Accepted \\
\hline \multirow{2}{*}{ Model 3 } & SC - FA & $<0.050$ & 0.000 & Accepted \\
& SC - IBB & $<0.050$ & 0.000 & Accepted \\
& FA - IBB & $<0.050$ & 0.010 & Accepted \\
\hline
\end{tabular}

Table 5 shows the three final models with all p-value that are significant for Each of them. Table 1 shows the direct effect, p-value, and $95 \%$ bias-corrected bootstrap confidence interval for the direct effect. There are nine hypotheses developed between the construct. Specifically, the result shown in Model 1 panic buying has a significant direct effect on fear appeal with a p-value of 0.00. panic buying has a significant direct effect on impulse buying behaviour with a $p$-value of 0.00. Furthermore, fear appeal and impulsive buying behaviour in model 1 are also significant, with a p-value of 0.027 . The result in Model 1 support $\mathrm{Hla}, \mathrm{Hl}$, and $\mathrm{HlC}$.

For the result tabulated in table 5, model 2 support H2a, H2b, and H2c. Government financial stimulus toward fear appeal has a significant effect with a p-value of 0.00 . Meanwhile, government financial stimulus has a significant effect on impulse buying behavior with a p-value of 0.013. Moreover, the fear appeal also has a significant effect on impulsive buying behavior in Model 2 with a p-value of 0.000 .

In summary, from direct effect, model 3 also support $\mathrm{H} 3 \mathrm{a}, \mathrm{H} 3 \mathrm{~b}$, and $\mathrm{H} 3 \mathrm{c}$. The scarcity of essential products has a significant effect on fear appeal with a p-value of 0.000 . In comparison, scarcity of essential products has a significant effect on impulse buying behavior with a p-value of 0.000 . Moreover, the fear appeal has a significant effect on impulse buying behavior in Model 3 with a p-value of 0.001 .

We went further to test the indirect effect. The indirect test supports our proposed hypotheses, such as $\mathrm{H} 4, \mathrm{H} 5$ and $\mathrm{H} 6$. So, the following table is the result: 


\section{Alfian Budi Primanto}

Rahmawati

\section{Table 6.}

Indirect Effect

\begin{tabular}{ccccc}
\hline Variable & Criteria & BootLLCl & BootULCl & Decision \\
\hline PB - FA - IBB & The range of & -0.009 & 0.219 & Rejected \\
GOV - FA - IBB & $\begin{array}{c}\text { BootLLCl and } \\
\text { ULCl should not }\end{array}$ & 0.110 & 0.293 & Accepted \\
SC - FA - IBB & consist of zero & 0.004 & 0.267 & Accepted \\
\hline
\end{tabular}

The bias-corrected bootstrap confidence interval has become the more widely recommended method for inferring the indirect effect in mediation analysis. A 95\% bias-corrected bootstrap confidence interval should be above zero if we accept the hypotheses. Table 6 shows that fear appeal mediates between panic buying and impulse buying behavior. The value of BootLLCl is 0.009 , and BootULCl is 0.219 . So that we reject the $\mathrm{H} 4$ and there is no significant effect between panic buying toward impulse buying behavior with the fear appeal as a mediation variable.

H5 obtained that fear appeal mediates between government financial stimulus and impulse buying behavior. Based on the table, the value of BootLLCI is 0.110, and BootULCI is 0.293. We could conclude that we accept $\mathrm{H} 5$. There is a significant effect between government financial stimulus on impulse buying behavior with the fear appeal as a mediation variable.

The last hypothesis in this research is $\mathrm{H} 6$ with the following statement, fear appeal mediates between scarcity of essential products and impulse buying behavior. Table 6 show that the value of BootLLCl is 0.004 and BootULCl is 0.267 . so that we accept $\mathrm{H6}$, and there is a significant effect. Scarcity of essential products toward impulse buying behavior with the fear appeal as a mediation variable.

\section{Discussion}

During Covid-19, there were several significant changes in shopping habits. The government policy regarding Lockdown and social distancing disrupted the consumer habits for shopping. Consumers are learning to improvise and learn new habits. This research finds that panic buying, government financial stimulus, and scarcity of essential products can influence impulse buying behavior.

Panic buying has a significant effect during the pandemic. They become panicked due to some pressure, and they have to survive. Consumers do panic buying in a pandemic situation triggered by other consumers who do the same thing. Customers buy in bulk because they anticipate changes in prices and product inventory. This study also found that panic buying was also 
dominated by hoarding a lot of essential and non-essential items during COVID-19. Customers tend to stockpile in large quantities to meet their needs during the pandemic. Our findings are similar to the previous study proposed by Yuen et al. (2020) argue that panic buying occurs when consumers buy products in enormous quantities in anticipation of a bad situation, large price increases, and a shortage of goods in the market. Likewise, the study conducted by Singh and Rakshit, 2020 has the same result as our finding. They mentioned that panic buying behavior appears when consumers buy products in large quantities to anticipate the scarcity of the product or the price increase when a disaster or crisis occurs. Furthermore, our finding is in line with, which indicated that panic buying is where the people even panicked and did impulse buying of groceries and other essential and non-essential items.

Government financial stimulus also has a significant effect, according to this research. The financial stimulus that citizens receive is unexpected money that drives more purchases. The government launched several programs as a form of assistance to residents during the pandemic. They spend most of the money to buy basic needs (groceries), medicines, and other basic needs. However, a few numbers of consumers in this research spend their money to buy unimportant products because they feel confused about what kind of product to buy. Our research finding somewhat agrees with previous research conducted by Addo et al. (2020) argued that people had spent this money on food (grocery items), sanitary, beer, and lottery. Thus, most of the purchases belong to the non-essential items because of impulse buying behavior. They argued that government financial stimulus plays a vital role in impulse buying behavior (Ahmed et al., 2020). Customers spend stimulus money from the government, especially on non-essential products, because easy money is the right impetus for impulsive buying behavior (CNN, 2020)

Furthermore, the perceived scarcity of essential products has a significant influence on impulse buying behavior. Customers are more involved in purchasing essential and non-essential items by looking at empty shelves. When shelves are empty, customers are encouraged to engage in impulse buying behavior. They compete to get products in large quantities to fulfill their desires, such as necessities, medicines, and other essential products, without concern for other consumers. Consumers will regret if they are not faster than other consumers who rush to stockpile goods in limited stock before they run out of stock. However, our finding was similar to Sheu and Kuo (2020) products that are expected to be inaccessible soon due to a health crisis are likely to threaten or limit personal freedoms or reduce access to products. Previous literature also showed that when news of COVID-19 spread, supermarkets, which normally had sufficient stock for every essential product item, suddenly ran out of stock due to panicked consumers who bought a lot of products 


\section{Alfian Budi Primanto \\ Rahmawati}

greedily (Kim and Su, 2020). They spread images of empty shelves and long lines of consumers on social media. This makes people tempted to make impulse purchases to buy essential and nonessential items through online and offline stores. (lyer et al., 2019; Addo et al., 2020)

This research finds that fear appeal significantly mediates government financial stimulus and scarcity of essential products toward impulse buying behavior. The fear of adjacent Covid-19 encourages them to buy plenty of products and stock items. The policy to stay at home and isolate themselves also encourages them to buy basic necessities in large quantities. Our finding has in line with Ahmed et al. (2020) mentions that fear appeal has a significant effect as a mediating factor on impulse buying behavior. Addo et al., 2020; lyer et al., 2019 also expressed the same suggestion, which indicates fear appeal was an important mediating variable during impulse buying behavior. However, prior research has similar findings stating that fear is a universal trigger of impulsive buying behaviour that may be enhanced because of the threat of harm, especially during the COVID-19 pandemic. (Öhman, 2005; Naeem, 2020)

The research finding should suggest several implications, especially for policymakers, government agencies, and marketers. To deal with crises during the Covid-19 pandemic, they should know the change of consumer behavior. They can come up with different strategies to meet customer expectations, especially in grocery shopping. Marketers can devise new strategies to increase their market share to achieve competitive advantage in future panic situations.

\section{CONCLUSION}

This study aims to examine the impulsive buying behavior of Indonesian citizens during the pandemic. We will also examine which variables influence impulse buying behavior during the pandemic. These variables include panic buying, government stimulus, and perceived scarcity. In addition, we also include fear appeal as a mediating variable on impulse buying behavior.

The research finds that panic buying, government stimulus, perceived of scarcity, and fear appeal have a significant effect directly on impulse buying behavior. We went a step further to test the indirect effects. The indirect test supports our proposed hypothesis using fear appeal as a mediating variable. The results showed that fear appeal did not mediate between panic buying and impulse buying behavior. Furthermore, fear appeal mediates between government stimulus and the scarcity of essential products on impulsive buying behavior. 
The constructs used in this study are neither comprehensive nor conclusive. We suggest further research to use other suitable variables to construct new constructs. The outbreak of the COVID19 pandemic is uneven, and we are in an unprepared situation. The data collected has limitations, including the duration and time of taking the questionnaire survey in this study is relatively short. Another limitation of this study is the specificity of data collection. The data were collected from Indonesian citizens who were severely affected by the coronavirus measures. Thus, the results cannot be generalized to other populations in the world. Therefore, future researchers are advised to conduct similar studies on a larger scale, including other countries, to confirm the dimensions of impulsive buying behavior.

\section{REFERENCES}

Addo, P.C., Jiaming, F., Kulbo, N.B. and Liangqiang, L. 2020. COVID-19: fear appeal favoring purchase behavior towards personal protective equipment, 40(7-8): 471-490.

Ahmed, R.R., Streimikiene, D., Rolle, J.A. and Duc, P.A. 2020. The COVID-19 pandemic and the antecedants for the impulse buying behavior of US citizens. Journal of Competitiveness, 12(3): $5-27$.

Anastasiadou, E., Chrissos Anestis, M., Karantza, I. and Vlachakis, S. 2020. The coronavirus' effects on consumer behavior and supermarket activities: insights from Greece and Sweden. International Journal of Sociology and Social Policy, 40(9-10): 893-907.

Arafat, S.M.Y., Kar, S.K., Menon, V., Kaliamoorthy, C., Mukherjee, S., Alradie-Mohamed, A., Sharma, P., Marthoenis, M. and Kabir, R. 2020. Panic buying: An insight from the content analysis of media reports during COVID-19 pandemic. Neurology, Psychiatry and Brain Research, 37: 100-103.

Baddeley, M. 2010. Herding, social influence and economic decision-making: socio-psychological and neuroscientific analyses. Philosophical Transactions of the Royal Society B: Biological Sciences, 365(1538): 281-290.

Bayer, n.d. The Coronavirus Stimulus Package: How Large is the Transfer Multiplier? by Christian Bayer, Benjamin Born, Ralph Luetticke, Gernot J. Müller:: SSRN.

Beatty, S.E. and Ferrell, M.E. 1998. Impulse buying: Modeling its precursors. Journal of Retailing, 74(2): 169-191.

Bellini, S., Cardinali, M.G. and Grandi, B. 2017. A structural equation model of impulse buying 


\section{Alfian Budi Primanto \\ Rahmawati}

behaviour in grocery retailing. Journal of Retailing and Consumer Services, 36: 164-171.

Brehm, J. 1966. A theory of psychological reactance. New York: Academic Press,.

Cheng, C., Barceló, J., Hartnett, A.S., Kubinec, R. and Messerschmidt, L. 2020. COVID-19 Government Response Event Dataset (CoronaNet v.1.0). Nature Human Behaviour, 4(7): 756768.

Chua, G., Yuen, K.F., Wang, X. and Wong, Y.D. 2021. The Determinants of Panic Buying during COVID-19. International Journal of Environmental Research and Public Health 2021, 18(6): 3247.

Clee, M.A. and Wicklund, R.A. 1980. Consumer Behavior and Psychological Reactance. Journal of Consumer Research, 6(4): 389-405.

CNN, n.d. People receiving stimulus checks get letter signed by President Donald Trump CNNPolitics.

Crabble, n.d. COVID-19's effect on consumer behavior in Asia-Pacific | Mintel.com.

David, J., Visvalingam, S. and Norberg, M.M. 2021. Why did all the toilet paper disappear? Distinguishing between panic buying and hoarding during COVID-19. Psychiatry Research, 303: 114062.

Fitzsimons, G.J. 2000. Consumer Response to Stockouts. Journal of Consumer Research, 27(2): 249266.

Gong, X., Zhang, H. and Fan, Y. 2021. To conform or deviate? The effect of resource scarcity on consumer preference for minority-endorsed options. Journal of Business Research, 122: 437446.

Grohol, J., n.d. Panic Buying: The Psychology of Hoarding Toilet Paper, Beans and Soup.

Gupta, R., Nair, K. and Radhakrishnan, L. 2021. Impact of COVID-19 crisis on stocking and impulse buying behaviour of consumers. International Journal of Social Economics.

Halim, A., Putra, P.K., Said, S. and Hasan, S. 2017. Implication of External and Internal Factors of Mall Consumers in Indonesia To Impulsive Buying Behavior. International Journal of Business Accounting and Management ISSN, 2(4): 2527-3531. 


\section{Jurnal Manajemen Teori dan Terapan Volume 14. No. 3, Desember 2021}

Hamilton, R., Thompson, D., Bone, S., Chapli.n, L.N., Griskevicius, V., Goldsmith, K., Hill, R., John, D.R., Mittal, C., O'Guinn, T., Piff, P., Roux, C., Shah, A. and Zhu, M. 2018. The effects of scarcity on consumer decision journeys. Journal of the Academy of Marketing Sciencea, 47(3): 532-550.

Hendrix, C. and Brinkman, H.-J. 2013. Food Insecurity and Conflict Dynamics: Causal Linkages and Complex Feedbacks. Stability: International Journal of Security and Development, 2(2).

Huang, L.T. 2016. Flow and social capital theory in online impulse buying. Journal of Business Research, 69(6): 2277-2283.

Huang, Y. and Zhao, N. 2020. Generalized anxiety disorder, depressive symptoms and sleep quality during COVID-19 outbreak in China: a web-based cross-sectional survey. Psychiatry Research, 288: 112954.

Iyer, G.R., Blut, M., Xiao, S.H. and Grewal, D. 2019. Impulse buying: a meta-analytic review. Journal of the Academy of Marketing Science, 48(3): 384-404.

Jones, M.A., Reynolds, K.E., Weun, S. and Beatty, S.E. 2003. The product-specific nature of impulse buying tendency. Journal of Business Research, 56(7): 505-511.

Joseph F. Hair Jr, William C. Black, Barry J.Babin, R.E.A. 2010. Multivariate Data Analysis.pdf.

Kacen, J.J. and Lee, J.A. 2002. The Influence of Culture on Consumer Impulsive Buying Behavior. Journal of Consumer Psychology, 12(2): 163-176.

Keane, M. and Neal, T. 2021. Consumer panic in the COVID-19 pandemic. Journal of Econometrics, 220(1): 86-105.

Kim, S.W. and SU, K.P. 2020. Using psychoneuroimmunity against COVID-19. Brain, Behavior, and Immunity, 87: 4-5.

Lin, Y.-H. and Chen, C.-Y. 2012. Adolescents' impulse buying: susceptibility to interpersonal influence and fear of negative evaluation. Social Behavior and Personality: An International Journal, 40(3): 353-359.

Lins, S. and Aquino, S. 2020. Development and initial psychometric properties of a panic buying scale during COVID-19 pandemic. Heliyon, 6(9): e04746.

Loxton, M., Truskett, R., Scarf, B., Sindone, L., Baldry, G. and Zhao, Y. 2020. Consumer Behaviour 


\section{Alfian Budi Primanto \\ Rahmawati}

during Crises: Preliminary Research on How Coronavirus Has Manifested Consumer Panic Buying, Herd Mentality, Changing Discretionary Spending and the Role of the Media in Influencing Behaviour. Journal of Risk and Financial Management, 13(8): 166.

MB, T., J, H., RS, Z., L, S., S, J., K, W. and D, A. 2015. Appealing to fear: A meta-analysis of fear appeal effectiveness and theories. Psychological bulletin, 141(6): 1178-1204.

Naeem, M. 2020. Understanding the customer psychology of impulse buying during COVID-19 pandemic: implications for retailers. International Journal of Retail andamp; Distribution Management, 49(3): 377-393.

Numerator Intelligence, n.d. Impact of Coronavirus (COVID-19) on Consumer Behavior in 2020 | Numerator.

Öhman, A. 2005. The role of the amygdala in human fear: Automatic detection of threat. Psychoneuroendocrinology, 30(10): 953-958.

Osés-Eraso, N., Udina, F. and Viladrich-Grau, M. 2007. Environmental versus Human-Induced Scarcity in the Commons: Do They Trigger the Same Response? Environmental and Resource Economics, 40(4): 529-550.

Parsad, C., n.d. Comparing between Product-specific and General Impulse Buying Tendency: Does Shoppers' Personality Influence their Impulse Buying Tendency?. Asian Academy of Management Journal.

Peels, R., Udenio, M., Fransoo, J.C., Wolfs, M., Hendrikx, T., NeoResins, D.S.M. and Fransoo, J.C. 2009. Responding to the Lehman Wave: Sales forecasting and supply management during the credit crisis, 5(2697): 1-20.

Piron, F. 1991. Defining Impulse Purchasing. ACR North American Advances, NA-18.

Poels, K. and Dewitte, S. 2006. How to Capture the Heart? Reviewing 20 Years of Emotion Measurement in Advertising. Journal of Advertising Research, 46(1): 18-37.

Riordan, D.M. and Singhal, D. 2018. Anxiety-related disorders: An overview. Journal of Paediatrics and Child Health, 54(10): 1104-1109.

Sheth, J. 2020. Impact of Covid-19 on consumer behavior: Will the old habits return or die? Journal of Business Research, 117: 280-283. 
Sheu, J.B. and Kuo, H.T. 2020. Dual speculative hoarding: A wholesaler-retailer channel behavioral phenomenon behind potential natural hazard threats. International Journal of Disaster Risk Reduction, 44: 101430.

Siddik, M.N.A. 2020. Economic stimulus for COVID-19 pandemic and its determinants: evidence from cross-country analysis. Heliyon, 6(12): e05634.

Singh, C. and Rakshit, P. 2020. A Critical Analysis to comprehend Panic buying behaviour of Mumbaikar's in COVID-19 era. undefined.

Steven, n.d. The New Politics of Strategic Resources: Energy and Food Security Challenges ... Google Books.

Suryaningsih, I. and Suryaningsih, I.B. 2020. HEDONIC SHOPPING MEDIATION ON IMPULSE BUYING DETERMINANTS. Journal of Management and Business, 19(1).

TS Chein, OT Hui, C.L. n.d. Factors Affecting Impulsive Buying Behaviour-Evidence from Malaysia.

U, D., n.d. Why Are We Panic Buying During the Coronavirus Pandemic?. Psychology Today.

Wei, K., Wen-Wu, D. and Lin, W. 2011 . Research on emergency information management based on the social network analysis - A case analysis of panic buying of salt. International Conference on Management Science and Engineering - Annual Conference Proceedings: 1302-1310.

Wiranata, A.T. and Hananto, A. 2020. Do Website Quality, Fashion Consciousness, and Sales Promotion Increase Impulse Buying Behavior of E-Commerce Buyers? Indonesian Journal of Business and Entrepreneurship (IJBE), 6(1): 74-74.

Xie LR, Chen JM, Z.M. 2013. Research on Influencing Factors on Panic Buying. Journal of Xi'an Technological University.

Yuen, K.F., Wang, X., Ma, F. and Li, K.X. 2020. The Psychological Causes of Panic Buying Following a Health Crisis. International Journal of Environmental Research and Public Health, 17(10): 3513.

Zheng, R., Shou, B. and Yang, J. 2021. Supply disruption management under consumer panic buying and social learning effects. Omega, 101: 102238. 